\title{
THE STONE HOUSES OF PINO PIZZIGONI: A RARE CASE OF VERNACULAR ARCHITECTURE IN THE UPPER TOWN OF BERGAMO (ITALY)
}

\author{
A. Cardaci ${ }^{1, *}$, M. Resmini ${ }^{1}$, A. Versaci ${ }^{2}$ \\ ${ }^{1}$ School of Engineering, University of Bergamo, Italy - alessio.cardaci@ unibg.it, monica.resmini@gmail.com \\ ${ }^{2}$ Faculty of Engineering and Architecture, University of Enna 'Kore', Italy - antonella.versaci@ unikore.it
}

Commission II - WG II/8

KEY WORDS: Vernacular Architecture, Conservation, Valorisation, Heritage at Risk, Social Housing

\begin{abstract}
:
Pino Pizzigoni was an architect from Bergamo whose work was characterized by a constant search for integration between tradition and innovation. The 'stone houses' built in the second post-war period in the Upper Town at the foot of the Medieval fortress and close to the Venetian Walls - a UNESCO World Heritage Site from 2017 - are an example of modern popular housing conceived to adapt to the needs of rural families who moved to the town. Designed under the Fanfani Law, they were envisaged to give new lifeblood to the ancient fabric, while respecting the landscape and the city's skyline. Today, they can be considered one of the most significant post-war contributions to the cultural and architectural debate of the entire region. Their particular geographical position of the settlement has protected the complex because falling in an urban section marked by environmental constraints. However, to date, the asset has not yet been subjected to any protective restriction by the Ministry of Cultural Heritage and so despite fifty years have passed since the architect's death and over seventy years since the construction. The large underground car parking, today under construction on the border of the building complex, in addition to compromising its structural stability, would cause dramatic changes on the landscape, transforming a place that resembled a mountain village in an area congested by traffic and deafened by the noise of cars and tourists.
\end{abstract}

\section{FROM THE RISANAMENTO OF BERGAMO ALTA TO THE SOCIAL HOUSING}

The Fanfani alla Fara houses designed by Giuseppe (Pino) Pizzigoni in 1949 are a rare example of vernacular architecture that has remained unscathed by time and fashion. The process leading to their realization is part of the complex debate about the historic city, which developed throughout the 20th century. A subject on which - from the XII International Housing and Regulatory Plans Congress held in Rome in September 1929 to the Gubbio Conference on the Preservation and Restoration of Historic Centres (1960) - just to mention the two moments of greater speculative intensity - diverging positions were taken. All focused to find comprehensive answers to the needs dictated by both modern life and the preservation of old centres.

A matter that Gustavo Giovannoni discusses in Vecchie Città and Edilizia Nuova (1931), assuming urban planning as the optimal tool to give the city those characters of continuity and decorum recently lost and to connect the problem of the preservation of monuments to that of building organisation (Zucconi, 2002). A lesson that finds practical application in the well-known Bergamo Alta Recovery Plan established by the engineer Luigi Angelini in the same years: a milestone in the advancement of the doctrines on architectural and urban restoration.

The experience of Bergamo Alta contrasts with other projects, which at the same time Italian exponents of the Modern Movement do and aim at the cancellation of the city's historic core, except for some significant monuments to insert in a new architectural and social design (Giambruno, 2007). It offers solutions that respect the environment of the monuments, then anticipating the argument on the grafting of new buildings into historic fabrics that will develop after the Second World War.
Angelini's program, founded on the in-depth knowledge of the morphological and stylistic characters of the architecture of the city and its territory, moves within a moderately creative conservation practice that consciously abstracts from introducing new buildings in the ancient centre. Even going as far as to suggest, for the eventual reconstruction of buildings, a design methodology based on the "respect for the planivolumetric dimensions of the existing buildings, on the use of traditional materials and of a compositional repertoire of architecture and decoration based on the principle of kopistenhaftes, selbstversichtendes Sichan- bequemen promoted by Riegl" (Scarrocchia, 1987, p. 207). A vision that coincides with that of the CIAM - preserving the ancient town and building the modern centre elsewhere - and which, moreover, had been confirmed by the realization - coordinated by Marcello Piacentini - of a Bergamo's new heart (1922-27) ${ }^{1}$ and by Giovanni Astengo's Bergamo Master Plan of 1969, an urbanistic tool with great reformist value. The construction of new social housing in Bergamo Alta, in the framework of the INA-Casa plan, is in a clear disruption with this approach. However, it belongs to the global and radical process of social, political and economic transformation experienced by Italy after the war and which assigns to the construction sector the role of promoter of the national rebirth (Di Biagi, 2010). The project awakens controversy and speculation that already in the early 1920s had inflamed the hearts of the citizens. A Luigi Angelini still clearly linked to the idea of isolating the monuments is opposed to the proposal of raising new social housing units on the esplanade of the Rocca ${ }^{2}$, judging them as an "enormous offence against the reasons for beauty" (Figure 1).

\footnotetext{
Corresponding author

1 The new business core, located downstream, in the lower part of the town, once occupied by the Fiera di Sant'Alessandro.

2 The imposing fortified complex from the 14th century, became under the Austrians partly private home and partly barracks and later transformed by the Italian government into prisons.
} 
The construction of these buildings seemed unthinkable to him, especially given the future restoration and reuse of the manor as a museum ${ }^{3}$ :

We can conceive the ineffable delight that could come to those who, looking out over the castle's parapets and patrol corridors to admire the city and the lines of the panorama from above, will see below a series of new roofs, balconies and smoking chimneys and a succession of popular vegetable gardens who knows how matching with the vastness of the environment and the breadth of the horizon? (Angelini, 1922).

A vision confirmed in 1948 when, following the will of the municipal administration to "admit the citizens within the old fence of the Venetian walls" and given the availability of land donated for this purpose by the Moroni Counts, he highlighted a series of technical, economic and artistic disadvantages linked to the new construction ${ }^{4}$. An opposition that he will later mitigate; as an honorary inspector of monuments, he will approve Pizzigoni's project, provided that the architecture designed was subordinated to the monumental constructions of the area; its materials, roofs, lights, etc. needed to be in line with the traditional character of the surrounding buildings ${ }^{5}$.

Certainly influenced by a series of constraints, the houses alla Fara are, therefore, the result of important studies that, since the Liberation, the architect had carried out with the aim of 'remodelling' the city of Bergamo. Through a policy truly active and attentive to all prospects of living (functional, economic, technological, aesthetic, material, and so on), he then believed that Italy will overcome the Second World War housing crisis (Wendt, 1962). To fully appreciate the project, it is, in fact, necessary to consider it in the framework of studies accomplished by the architect on minimal and popular housing. In-depth research on the articulation of volumes and on the functionality of the environments that led to a very personal typological experimentation linked to the genius loci in all its parts, tangible and intangible.

\section{THE INA-CASA PLAN AND ITS IMPLEMENTATION IN BERGAMO ALTA}

The events related to the construction of the alla Fara houses are consequent to the approval of the Measures to increase workers' employment, facilitating the construction of houses for workers (Law no. 43 of 28.02.1949), known as INA-Casa plan or Piano Fanfani. Architectural and urban planning operations were entrusted to the INA-Casa Management; the local institution (Municipalities and Autonomous Institutes for Popular Houses-IACP) played the role of contracting stations to implement interventions (Di Biagi, 2003, 2010, 2013).

To help them and provide designers with some guidelines for the drafting of the projects, the INA-Casa Management, chaired by Arnaldo Foschini with the collaboration of Adalberto Libera and Mario Ridolfi (Nicoloso, 2001), published in October 1949 a first booklet containing guidelines and a certain number of examples of plans for social housing.

\footnotetext{
3 The complex was transformed between 1923 and 1928 by numerous demolitions around it including part of the so-called Casa della Marchesa to build the Parco delle Rimembranze and finally bound in 1982. In this regard, see the report attached to the binding decree $n$. 198 of $18 / 10 / 1982$

4 Bergamo, Archivio ALER, Verbali del Consiglio, registro 8, 12.02 .1948 , p. 83 , punto "g".

5 BCBg, Licenze edilizie, 10.03.1950.
}

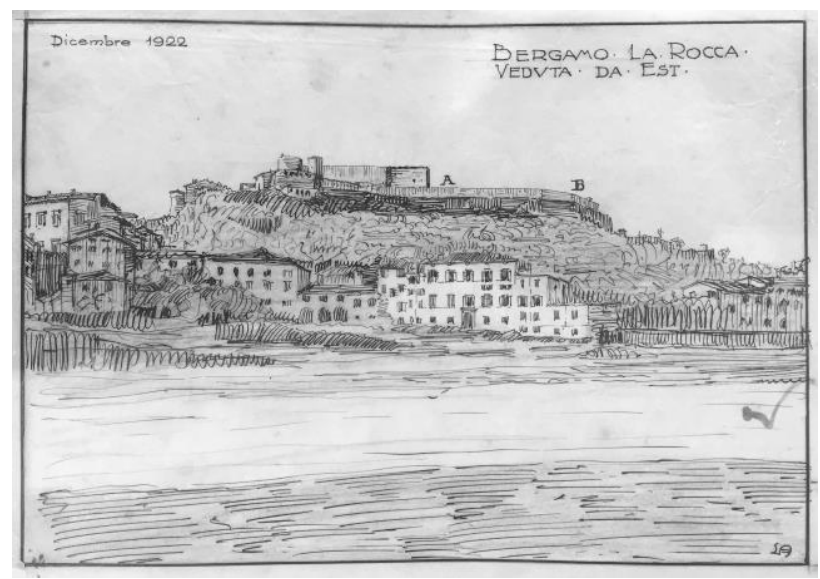

Figure 1. The Parco della Fara by Luigi Angelini (1922). On the right, among the 'wild' vegetation, the former convent of San Francesco.

As mentioned in the title, these suggestions were intended not to limit the creativity of the designers, who must, however, take into account "the local problem from every point of view (lifestyle, local traditions, climate, latitude and altitude, local building materials, handicraft products, workers, construction systems, heating" (INA-Casa 1949, p. 9). The application of these rules led in some cases to the adoption of the vernacular repertoire "to confer to the building an apparent spontaneity and an artificial harmony with the place" (Poretti 2002, p. 23).

Regarding the importance of the genius loci, the booklet recalled the need for the enhancement of landscape resources through their visual enjoyment by the local population and underlined that the respect for the existing green areas should guide any layout (INACasa 1949, p. 11). Engineers and architects were invited to present their proposals by participating in the competitions (focusing on mainly architectural or technical-constructive characters) listed in the same brochure (Capanna, 2005). The competitions aimed to select the technicians to whom the contracting stations will address for the drafting of the project (Nicoloso 2001, p. 93).

At the beginning of 1950, the first list of 202 suitable architects and engineers ${ }^{6}$ was drawn up, including the engineer from Bergamo, Pino Pizzigoni, a talented professional, professor of drawing at the Carrara Academy, a pupil of Giovanni Muzio and president of the CIAM organizing committee, which was held in Bergamo a year before (Figure 2).

The list of selected professionals was forwarded to the IACP of Bergamo, identified as the contracting authority for INACasa constructions. The regulations foresaw that the executive project could be presented according to a shortened procedure that avoided the examination of the preliminary project if the author was one of the chosen professionals. Accordingly, the IACP Council decided to entrust Pizzigoni with the task of carrying out the project awarded under the competition ${ }^{7}$.

The design of this social housing, envisaged in a particular landscape context north-facing, offered Pizzigoni a chance to redeem after a long period of very little work during the regime due to his political position (Spagnolo, 1982). His

6 Thanks to Paolo Nicoloso and Ferruccio Luppi for providing the list of suitable candidates kept in the Archivio ATER diUdine, B.T. 134.

7 Bergamo, Archivio ALER, Verbali del Consiglio, registro 9 , 28.01.1950, pp. 72-74, punto 2 . 
proposal sought to answer two major problems arising from the site. One linked to the hygienic-sanitary question "being the area, steep and facing exactly north behind the bulwark of the fortress"; the other to the Superintendency of Monuments "being a wilderness area which contributes to give character to the profile of the old city"8.

\subsection{The architectural language and the close relationship with the genius loci}

The architectural language employed by Pizzigoni is a mature synthesis that refers to past works and/or to project proposals never made. The arrangement of the spaces around a central plan and on a single floor is a development of the projects established on 1945 for the Banca Popolare di Bergamo's building initiatives; the long inclined ramp for the aggregation and distribution of the individual units is a clear reference to the 1932 design of Villa Ardiani in Selvino, while the skylights - similar to the factory sheds - and the inclination of the roofs, studied in reason of maximum sunshine, recall the minimum house of 1946 (Figure 3). The houses in via Fara are a small jewel that marks the pinnacle of the typological studies carried out by Pino Pizzigoni. After this experience, he will transfer his interest towards structural and formal aspects, preferring the use of reinforced concrete and thin double-curved vaults to the heavy brick and stone constructions typical of the mountain building tradition.

The same project is, in the use of materials, an exception; a path taken to then be abandoned, in which:

The context of the Upper Town and an organic and historicist vision seem to affect the final design choice [...] focusing on those environmental and historical issues on which architectural culture was increasingly paying attention, to the point of placing this project in close relationship with that 'neorealist' architecture which then took its first steps in Italy. (Pizzigoni 2005, p. 159).

His idea is, therefore, to design an architectural complex that instinctively dialogues with the place, without hiding it. Buildings are conceived to combine with the horizon of the fortress while maintaining their recognizable quality. A search for integration with the environment as shown by the choice of materials - the grey sandstone of Selino (in Valle Imagna) and the dark slates of Branzi for the cladding of the thick brick walls and the roof coverings - and the accurate design of wooden window frames and light and non-invasive railings "with the possibility of windowsill flower arrangement"9.

A series of edifices that "seen from the east, i.e., from the underlying large open space of Sant'Agostino would have no profile; then, seen from the north, i.e. from the Valtesse valley, would present only the roofs so to result completely camouflaged; seen from the south, i.e. from the walls of the Rocca, would still present only the roofs; and finally, along the Fara by-pass, would preserve the view of the main foot of the fortress"10.

8 Bergamo, Biblioteca Civica A. Mai and Archivi storici comu- nali (from now on BCBg), Archivio Pizzigoni, PIZ.A.48, fasc. Bergamo, via Fara, Case a schiera per lavoratori da costruirsi nell'ambito dei programmi della legge Fanfani, 1949, manuscript [1950]. For photographs n. 1, 3-8, we thank the Biblioteca Civica Angelo Mai for granting the publication.

9 Ibidem.

10 Ibidem.
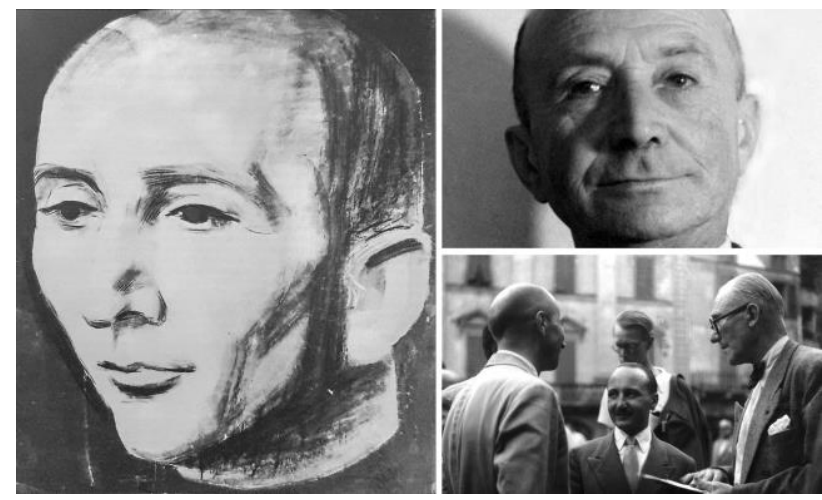

Figure 2. Pino Pizzigoni: two portraits (as a young man and in adulthood) and a photo with Le Courbusier at the CIAM 1949.

A 'machine for living in' meticulously conceived, especially in size and layout that, by adapting to the slope, raised and lowered. "In some cases, the housing plan will arise immediately from the land [...], while in other cases it will be necessary to create a non habitable ground floor, to be used as closet attached to the garden"11, to offset the heights of the apartments and allow them to receive as much light as possible.

\section{THE EVOLUTION OF THE DESIGN}

In February 1950 Pizzigoni presented to the Building Commission a first rough solution ${ }^{12}$, which combined a typological complexity with a unitary and organic structure similar to a fortified building. An architecture embedded in the landscape, not a juxtaposition of simple volumes, but an imposing monolithic construction, which from the land raised in the direction of the Rocca up to three floors. A mass of stone that, by adapting itself to the valley, characterized the landscape, adding formal value to the bastion of the Rocca and the convent of San Francesco.

An image represented in a famous architect's drawing that well communicates the architecture while forgetting, however, to reproduce the indomitable vegetation, so giving a more metaphysical than realistic vision (Figure 4)



Figure 3. Design references: the 1947 'minimum house' (left), the 1932 Villa Ardiani in Selvino (middle), the 1945 project for the Banca Popolare di Bergamo's building initiatives (right).

\footnotetext{
11 Ibidem.

12 BCBg, Licenze edilizie, 14.02.1950.
} 
The design began with the careful study of the topography of the site, through the accurate survey of the altitude, the maximum slopes, the drawing of the contour plots.

The first sketches highlight a designer's almost obsessive interest in finding the optimal positioning for the apartments, twelve in total, operated through careful calculations of the altitude of the sun at both the summer and the winter solstice when the solar star reaches the point respectively of maximum and minimum declination.

The presence of the high bastion of the fortress, whose shadow would project onto the houses, suggested to the architect to position them as close as possible to via della Fara and to create a small retaining wall to raise them and so reduce shading.

The architect proposed a version of the housing complex, as a single body hinged on an inclined distribution axis; the slope of the long disengagement ramp and roofs, equal to 24 degrees 30 minutes, was calculated to allow "the sun to cross the stairs in the two months of winter" (Figure 5).

The housing units, which reproduced the solution presented in the autumn 1949 competition, despite the central staircase, enjoyed both the east-facing with the living area, and the westfacing with the sleeping area. A small entrance allowed access to a single open space environment with kitchen-living space; on the opposite side, a small bathroom was located in correspondence of the hallway with the bedroom area (three rooms in total, of different sizes, two smaller single rooms and a larger double room). A too 'risky' solution that was modified in the final version by reducing the size of the apartment, envisaging closed kitchens and only two sleeping rooms.

The simple and regular façades presented small balconies in correspondence with the day room and the double bedroom. Particular care was paid to align, on the same horizons, the windows of apartments located at different levels by regulating the wine cellars' heights (Figure 6).

The plans show a very particular dimensioning system, which however connotes the entire architect's production, with unusual and precise centimetre accuracy in the measurements (for example, room sizes of $4.21 \mathrm{~m} \times 3.88$ instead of $4.20 \times 3.90$ ). An extremely precise attitude, certainly not compatible with the normal requirements of the construction sites, which denotes an almost mathematical approach to design. Exact measurements that are present only in a few cases, as for the perimeter walls of $50 \mathrm{~cm}$. The dimensions of the internal non-structural walls are very particular, only $12 \mathrm{~cm}$ for the separation of the different apartments and $8 \mathrm{~cm}$ for the internal partitions (Figure 7a).

The project had the blessing of the Superintendency on 1st March 1950 and that of the Construction Commission on the following 10th March. At the same time, a copy of the proposal was forwarded to the INA-Casa management offices in Rome asking for a substantial variation of the project.

On 17th April 1950, Pino Pizzigoni presented a second version of the project, in which he sacrificed the idea of a unitary building to propose an aggregate of six two-storey terraced building units, placed on floors with staggering levels and connected through an external pedestrian path. For each building unit, two small gardens - the one facing east on the ground floor and the other facing west on the first floor - were envisaged as extension of the house. Small external stone stairs with a simple metal railing, typical of the Lombardy tradition (Bertelli et al., 1994), allowed access to the residences on the upper level.

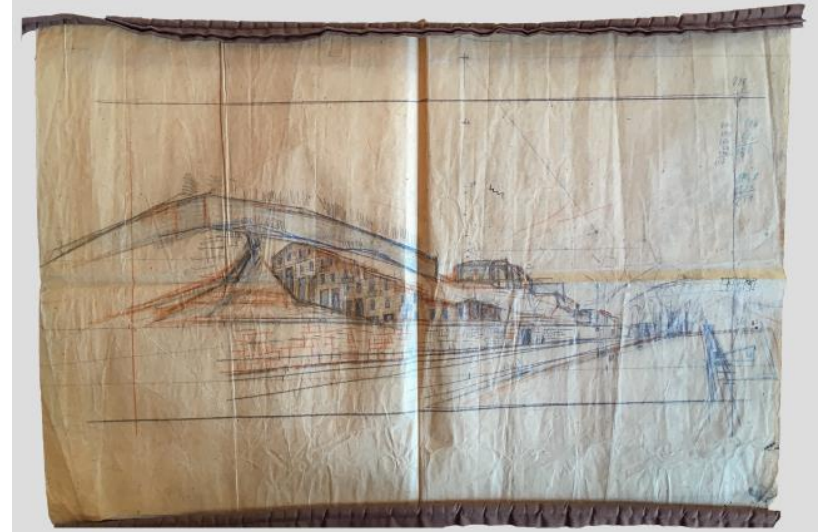

Figure 4. A perspective view of the first draft of the project, probably the version awarded by the INA-Casa and approved by the Urban Planning Commission of Bergamo on 10 March 1950.

The plan was not dissimilar from the first version - to which the central part of the ramp hallway was removed, losing the wardrobes and the internal closet - and was set in a living area with a small bathroom that connected the sleeping area with two rooms. Even in this case, the basements of the houses adapted to the ground; the first four were established at the same level of foot traffic while the last two, towards the Rocca, were differently raised. This still allowed perceiving the entire volume, also thanks to the inclination of the roofs that all lowered towards the north (Figure 7b).

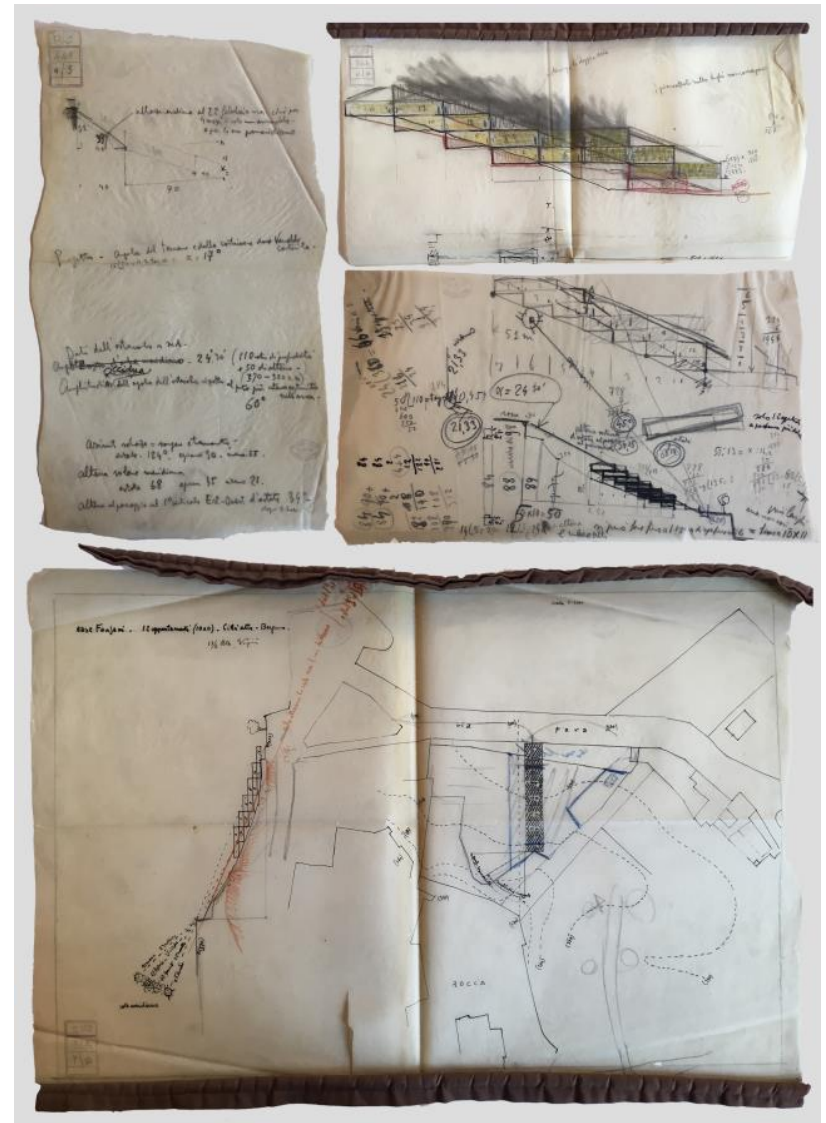

Figure 5. The planivolumetric study that indicates particular attention of the architect to the choice of the optimal positioning of the apartments operated through careful calculations of the altitude of the sun at the summer and winter solstices. 


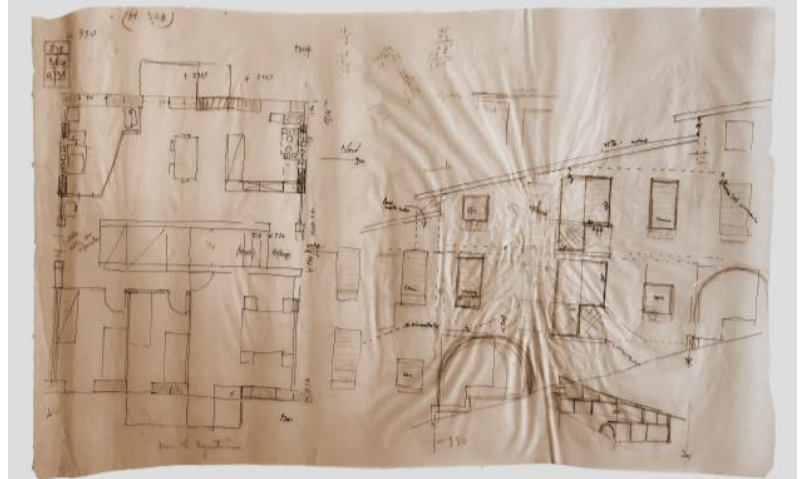

Figure 6. The study of the internal distribution of the apartments (in the version of the sleeping area with three bedrooms) and of the lateral façade with the vaulted cellar floor).

The project still underwent a third revision and a further simplification of volumes and geometries; unfortunately, there is a lack of information on these adjustments in the old documents in the archives, but it was probably linked to economic issues.

To reduce the terraces and the levelling of the area, the buildings were positioned at a lower altitude and staggered in height all of the same sizes; the single-pitched roofs were lowered, rotated 90 degrees and, set on the spine wall, transformed into two pitches. The slate roofs were instead imagined in terracotta and the upper floor entrance moved to the corner to relocate the stairs and create a window for the bathrooms (Figure 7c).

A volumetric composition that has become perfectly regular and repetitive, so deeply differing from the architect's experiments. Nonetheless, the houses are one of the most significant post-war contributions to the cultural and architectural debate of the entire region. By them, Pizzigoni intended to suggest a new way of living in the Upper Town similar to that of mountain villages, through the use of local stone for the cladding, the presence of a vegetal garden for each apartment, lower terraced units that over- looked the street to reinforce among the inhabitants, the social and neighbourhood bonds.

A way of thinking about the house linked to a tradition that was very far from the boldness of the block, the tower residences and condominiums of the new expansions: a unique example in the historical context of Bergamo Alta, today faced with pressures which could have negative effects on its values.

\section{THE ALLA FARA'S HOUSES AND THE CONSE- QUENCES CAUSED BY THE TOURISM INDUSTRY}

The alla Fara houses are the emblem of a housing complex that strives to dialogue, actively and at the same time in a balanced way, with the historic fabric of the Upper Town, so determining "the affirmation of a new culture of living in social houses" (Spagnolo, 2001, p. 118; Bertelli et al., 1994). They are artefacts that - as in many analogous cases attributable to the INA-Casa experience - draw references and ideas "from that minor urban fabric that, beyond the ages and locations, reflects, in an over historical dimension, the local craft traditions and the characters of minor architecture" (AA.VV., 2016, p. 15). A contemporary architecture placed in the historic centre of Bergamo, close to the Venetian walls - since July 2017 inscribed on the UNESCO World Heritage List - and strongly admired by both the local and the international community, although alas not yet listed despite its undeniable cultural and artistic interest (Figures 8 and 9). A place to safeguard, therefore, but which is now threatened by the construction of a maxi-car park (nine floors with 500 parking spaces) currently underway, despite the countless criticisms and complaints carried out in Bergamo and beyond.

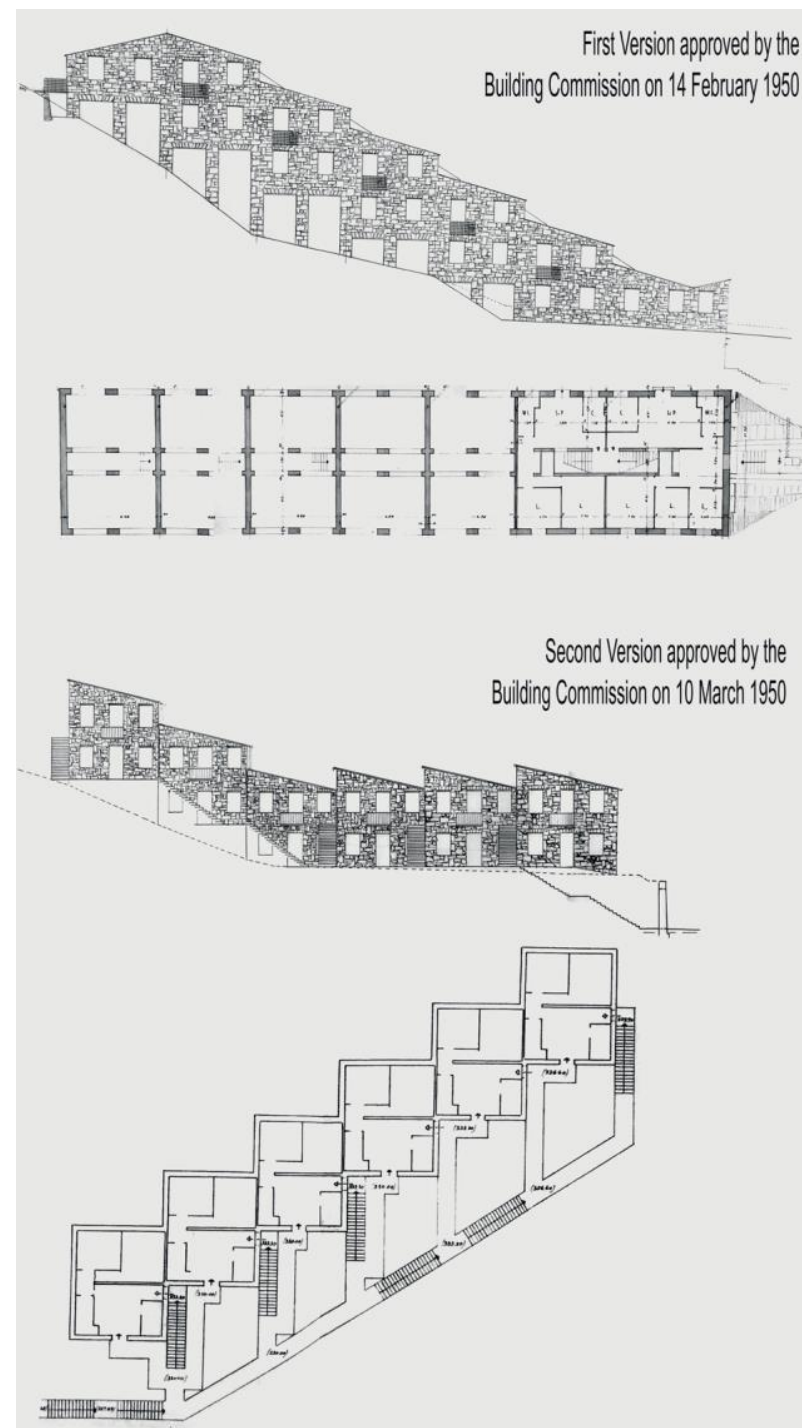

Third Version - the project built

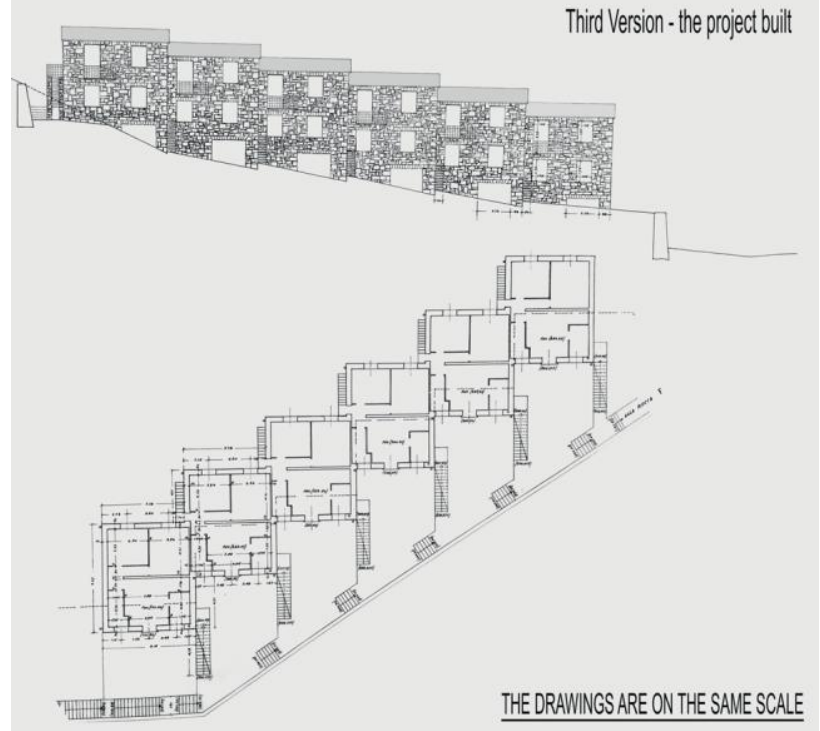

Figure 7. The three versions of the project: a) the first version approved by the Building Commission on 14 February 1950 (top) - b) the second version - after the changes requested by Ente Gestione Ina-Casa in Rome - approved by the Building Commission on 10 March 1950 (middle) - c) the third version after the variants to reduce construction costs (down). 

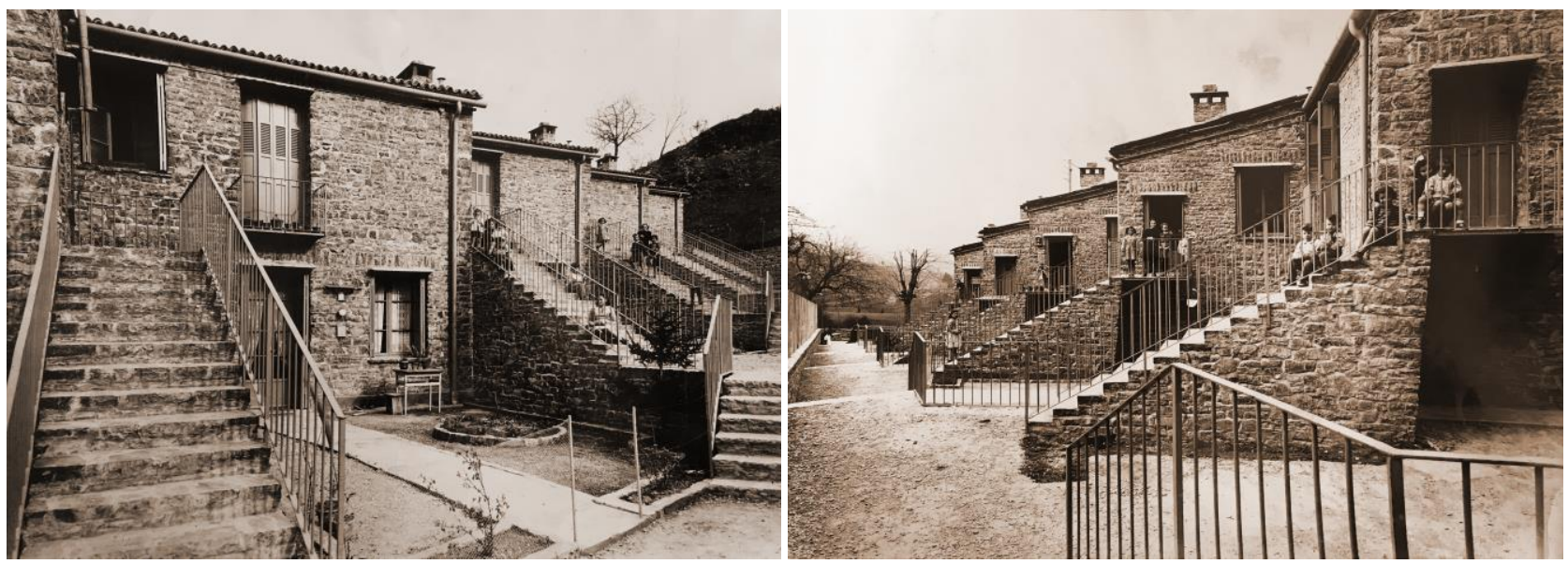

Figure 8 . The Fanfani alla Fara houses after the construction in the 50s of the last century.

The project for the parking in via Fara dates back to 2003 and was approved in 2004 although in contrast to the guidelines of the Detailed Recovery Plan of Città Alta (PPRCA) $)^{13}$ - which provided for a series of small/medium-sized parking lots for residents and commercial operators and interchange parking lots outside the circle of the walls, to be connected to the historic centre through a system of ascents -, as well as with the provisions of the Regulatory Plan (now the Territorial Government Plan) and the Territorial Plan of the Hills (Figure 10).

In December 2008-January 2009, the area was struck by a serious landslide movement, which called for significant consolidation activities. The parking is located in a historically fragile area from a geological point of view, which has already suffered numerous collapses in the past, including part of the northeast wall of the Rocca.

A thorny project, which, although not configured as a real 'ecomonster' - since it is an underground structure - is straining the seabed of the Pizzigoni houses: masonry structures designed from a structural point of view only with static criteria and therefore vulnerable to dynamic stresses induced by the new construction (both in the building and operating phases).

A questionable choice made by the Municipal Administration aimed at freeing the squares and the streets of the Upper Town from cars, moving those of the residents near the walls into the approximately 220 stalls - now assigned to non-residents - and those of visitors in the new parking garage. A car park designed 'for tourists' (as admitted by the same municipality) according to urban planning strategies that reverse the priorities, and are nonresilient and undemocratic. Strategies that will most probably result in the "destruction of the social structure, the museification of the monumental fabric, the gentrification", transforming the city into a backdrop for films, a location for events (Montanari, 2018). By moving the entrance road of the city to via della Fara, the new car park subjugates the Fanfani houses to the unfortunate consequences of car traffic, breaking the long-established relationships with the surrounding environment.

Although built according to maximum economic criteria, the houses were so far kept in a good state of conservation; the ordinary variations made over time to adapt them to the new housing standards were operated in an organic and nontraumatic way. The care given to the buildings by the owners has allowed the exterior to maintain a fairly faithful appearance to the original, except for a few canopies installed on the entrance doors of the first floors and the presence of new skylights on the roof of a house that denounces the creation of internal mezzanines. A harmonic situation, now at risk, in a Bergamo Alta that urgently needs clear policies aimed at reducing the adverse effects of tourism.
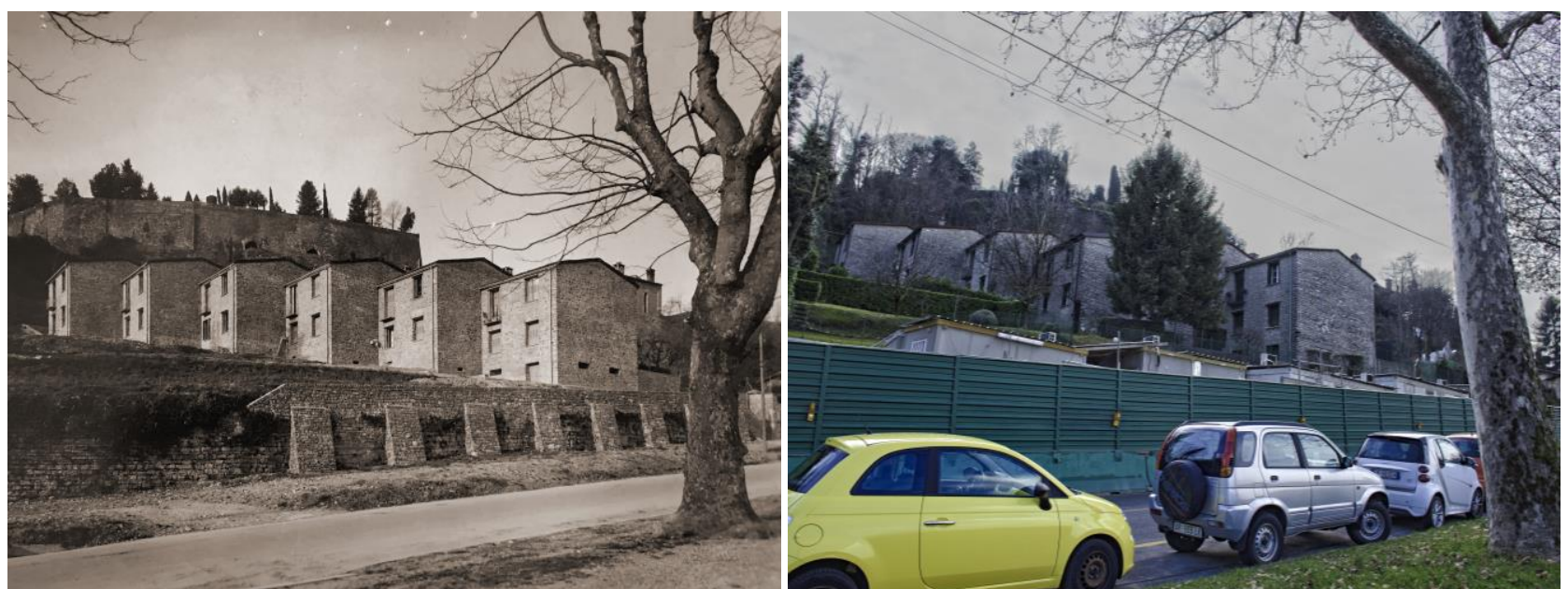

Figures 9. The Fanfani alla Fara houses views from the Venetian Walls (a comparison between yesterday and today).

13 Adopted by Municipal administration resolution of 26/04/2004 and approved in 2005. 


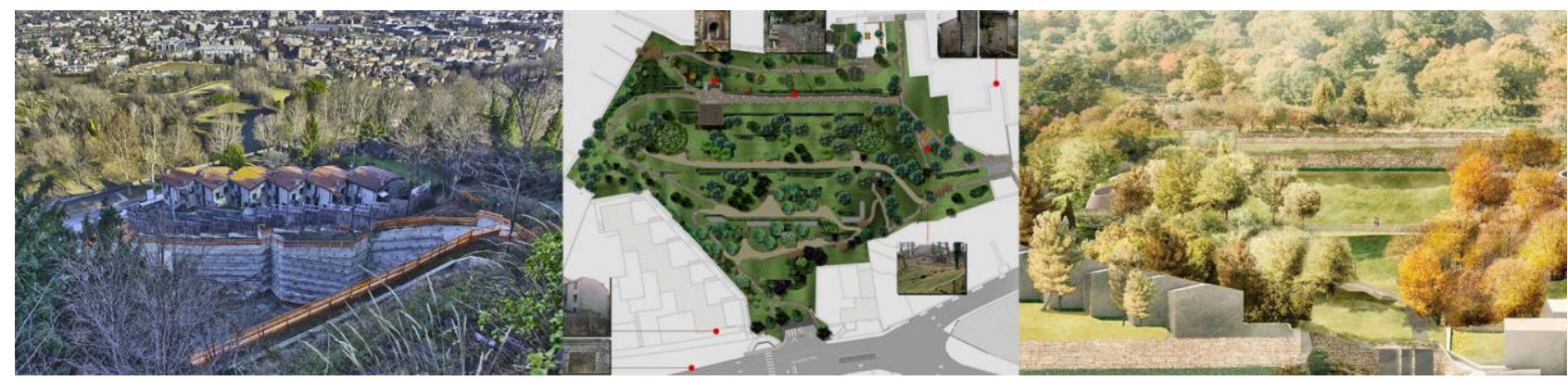

Figure 10. The construction site of the new parking in via Fara.

\section{CONCLUSIONS}

The importance of Pino Pizzigoni's project can only be understood if studied within that particular context, identified by recent historiography with the term Neorealist architecture, which influenced the first seven years of the INA-Casa plan's implementation. Neorealism wanted to answer the needs dictated by the reconstruction through the "rediscovery of a peasant purity (which) was (was) only a chapter of a cultural populism in Italian post-war culture (...) a regressive utopia with nostalgic accents" which will disappear in the years of the economic boom (Tafuri, Dal Co, 1976, p. 366).

Planned during this period, the Case alla Fara, are an excellent expression of a new compositional design that has managed to blend innovation and tradition. They are characterized by a renewed typological differentiation combined with the use of local materials and simple and consolidated construction techniques. The aim was to give that familiar 'sense of natural spontaneity' necessary to new inhabitants often coming from rural contexts (Camoglio, 2020). It was also intended to enhance the employment of local workers and so to relaunch an economy affected by the conflict.

The houses have an atypical nature because they are a small intervention in the continuity of the existing building and the fortress, as opposed to the large residential neighbourhoods of the suburbs. They are a hidden icon of modernity manifested in refined typological research focused on the people rather than in the use of the cement conglomerate and/or prefabricated technologies. This paper, while sharing the same documentary sources with previous studies, highlights aspects that have been neglected to date. In particular, the careful study of the unfinished designs and sketches of the architect has revealed, contrary to what has been claimed up to now, the existence of as many as four design variants instead of two. There is a phase following the first design idea in which Pino Pizzigoni while abandoning the idea of a large central space as primary thoroughfare of the house, does not renounce the 'single volume' and the great liveliness of the individual housing units that rest on the morphology of the existing land. On the other hand, the latest version foresees six small units placed on a single regular and uniform terrace; an aggressive solution that includes the modification of the natural slope with important excavations, probably justified by cost savings in building foundations.

To date, there are still many questions related to the choices that have influenced the design changes; in particular, there are no known documents that allow us to understand what the influence of INA headquarters was in drafting the new projects and if the architect was asked to adapt to more consolidated solutions based on the INA-Casa's guiding plans.
The design choices of Pino Pizzigoni have also undergone heavy changes during the construction site; a phase in which the designer was also excluded from the direction of the work entrusted to another technician. The roof imagined by Pino Pizzigoni in grey slate will be replaced by a mantle of red roof tiles, as well as other construction solutions for the construction of the floors and decks. Still, the small rear stairs to reach the gardens will not be built, even following the decision to raise the quotas of the cellars and redesign the areas intended for small private gardens, to the great disappointment of the same designer.

It is hard to speculate whether Pizzigoni's project was dictated by his openness to the vernacular and interest in rural architecture or if the reasons are a compromise solution to satisfy the landscape constraint. However, the housing complex remains an episode of particular originality both in Pizzigoni's architecture and in the context of the city of Bergamo.

An exceptional event, which, due to its exceptional conditions, deserves to be known, preserved and valued as historical and mo- numental memory in the context of the Upper City.

\section{REFERENCES}

AA. VV., 2016. L'architettura INA Casa (1949-1963): aspetti e problemi di conservazione e recupero. Gangemi, Roma.

Angelini, L., 1922. Ancora per le case popolari sulla Rocca. L'Eco di Bergamo, 28 novembre 1922.

Bertelli, G., Invernizzi, M. Brambilla, M., 1994. Bergamo: cent'anni di architettura, 1890-1990. Alcom, Bergamo.

Camoglio, G., 2020. Vernacolo e comunità nell'era della tecnica. ARK. Rivista Trimestrale di Architettura, 33(1), 18-24.

Capanna A., 2005. La casa per tutti. Il primo concorso INACasa e la ricostruzione civile del Paese. Rassegna di architettura e urbanistica, 117, 78-85.

Di Biagi, P., 2003. Quartieri e città nell'Italia degli anni Cinquanta. Il piano Ina Casa 1949-1963. Mélanges de l'École française de Rome. Italie et Méditerranée, numéro thématique: Politiche scientifiche e strategie d'impresa nella ricostruzione. Un confronto Francia-Italia. Police et contrôle du territoire dans les villes capitales (XVIIe-XIXe siècle), 115(2), 511-524.

Di Biagi, P., 2010. La grande ricostruzione: il piano Ina-Casa e l'Italia degli anni Cinquanta. Donzelli, Roma. 
Di Biagi, P., 2013. Il Contributo italiano alla storia del Pensiero, Tecnica. Il piano INA-Casa: 1949-1963. Roma, Treccani. (websites: http://www.treccani.it/enciclopedia/elenco-opere/ Il_Contributo_italiano_alla_storia_del_Pensiero:_Tecnica)

Giambruno, M., 2007. Per una storia del Restauro Urbano. Piani, strumenti e progetti per $i$ Centri storici. Citta Studi Edizioni, Novara.

INA-Casa (ed), 1949. Piano incremento occupazione operaia. Case per lavoratori, 1. Suggerimenti, norme e schemi per l'elaborazione e presentazione dei progetti. Bandi dei concorsi (fascicolo 1), Roma.

Montanari, T., 2018. La bellezza inutile delle città. Il Fatto Quotidiano, 5 novembre 2018.

Nicoloso P., 2010. Gli architetti. Il rilancio di una professione, Di Biagi, P. (ed). La grande ricostruzione: il Piano INA-Casa e l'Italia degli anni '50. Donzelli, Roma, 77-97.

Pizzigoni, A., 2005. Abitare lo spazio: la proposta architettonica di Giuseppe Pizzigoni per la ricostruzione edilizia. Pugliese, R. (ed), La casa popolare in Lombardia: 1903-2003. Unicoopli, Milano, 56-160.

Pizzigoni, A. (ed). Pizzigoni, invito allo spazio: progetti e architetture 1923-1967. Electa, Milano.

Poretti, S. (ed), 2002, L'INA Casa. Il cantiere e la costruzione, Gangemi, Roma.

Scarrocchia, S., 1987. Bergamo alta di Luigi Angelini. Restauro e Città, 5-6, 207-212.

Spagnolo, R., 2001. L'architettura a Bergamo tra tradizione e nuovi linguaggi. Rodeschini Galati M. C. (ed), Arte a Bergamo 1945-1959. Lubrina, Bergamo, 16-137.

Spagnolo, R., 1982. La ricerca tipologica per la costruzione della città. Pizzigoni, A. (ed). Pizzigoni, invito allo spazio: progetti e architetture 1923-1967. Electa, Milano, 68-79.

Van den Bergh, W., Motta, L. (2011), Giuseppe (Pino) Pizzigoni: 1901-1967, Bergamo. Local Heroes, 7, 1-35. (websites:

https://www.academia.edu/5990322/Giuseppe_Pino_Pizzigoni_ 1901-1967_Bergamo_Local_Heroes_7_Pino_Pizzigoni_

Bergamo._by_Wim_van_den_Bergh_and_Luciano_Motta).

Tafuri, M., Dal Co, F., 1976. Storia dell'architettura contemporanea. Electa, Milano.

Wendt, P.F. (1962). Post World-War-II: housing policies in Italy. Land Economics, 38(2), 113-133. (websites JSTOR: https:// www.jstor.org/stable/3144613).

Zucconi, G., 2002. Un manuale mancato. Giovannoni, vecchie città ed edilizia nuova, 1931. Di Biagi, P. (ed.), I classici dell'urbanistica moderna. Donzelli, Roma, pp. 55-69. 